\title{
Move Odyssey in China: rural-urban migration and subsequent relocation in cities
}

\author{
Bingxue Han \\ School of Urban-Rural Planning and Landscape Architecture, \\ Xuchang University, \\ 461000, China \\ E-mail: hanbingxue0451@163.com
}

\begin{abstract}
It may be a long series of wanderings or adventures filled with notable experiences and hardships that a rural person in current China migrates into urban area and attempts to relocate in it. Hukou conversion, family separation, and job opportunity become the three main barriers for rural migrants transform into urban citizen. Academic identification has verified there is full of risks for the expectations and consequences of residential mobility in China as to a rural family. An empirical exploration is necessary to examine the role of hukou conversion and marriage in the mechanism of residential mobility. However, lack of the most appropriate dataset, CHARLS dataset becomes the second-best. The empirical results reflect residential mobility dynamics in China have destroyed the original system of rural family. The waiting time of hukou conversion has exhaust youth and vigour of migrants. The regression analysis provides a further insight of economic variables including years prepared for moving within the county/city and years prepared for moving into the county/city. The subsequent discussion expands understanding millions of migrants' adverse situations, the positive and negative impact of multiple social forces on their lives. In the end, direction of future research is discussed.
\end{abstract}

Keywords: Odyssey; residential mobility; cities; hukou conversion; relocation; migration; migrant; CHARLS; China.

Reference to this paper should be made as follows: Han, B. (2014) 'Move odyssey in China: rural-urban migration and subsequent relocation in cities', Int. J. Migration and Residential Mobility, Vol. 1, No. 1, pp.12-27.

Biographical notes: Bingxue Han is an Advanced Lecturer in Xuchang University. Her main research fields include environmental management and construction economics, especially residential mobility among regions, marriage and family-related health and housing upgrade in China. She has published nearly 20 papers. And, part of her papers are indexed by EI and ISTP.

\section{A story}

Imagine that you are born in rural China before 1978. You get the agricultural household registration system (or hukou in Chinese). ${ }^{1}$ What is agricultural hukou? China's hukou is an institution controlling population movement. The city and the country are really two 
different worlds. As a rural person, you wish to make a better life in urban China. You prepare for the objective. You are driven by the 'push' factors and the 'pull' factors to move from a rural area to an urban area. 'Push' factors are rural areas are less job, cultural and social opportunities than urban areas. 'Pull' factors are that urban areas tend to have more job opportunities, better schools, cultural and social amenities. Coupled with the continuing decay of rural infrastructure projects in a struggling economy, you are forced to migrate to urban areas. Constrained by poor background, you have to find a job in urban place. You have to face more family separation in the cost of feelings in order to get small money.

Involved in straitened circumstances in cities, you become one of floating population. You take the temporary form of migration, with double (rural and urban) residential status. You hope that you can settle down in the cities and be fully integrated into China's urbanisation process. Ideally, you would want to compare the outcome of migration for stay when you participate in the market economies to the outcome for these same workers when they do not participate. At the same time, you conceive and compare the cost-benefit of residential mobility in cities. Unfortunately, you suffer from discrimination by local residents. Although the beautiful night view of the city can help alleviate this mental stress, discrimination will still remain if you have to be in contact with urban persons. You believe nothing difficult cannot be conquered, if you are confident of your future. Challenging conditions are not unexpected in urban China, you say. You cannot expect these places to have the satisfactory matters of a rural China. You just have to deal with it. When you are employed by a boss, you may be afraid you can not get the payment in time due to boss' cheat. More importantly, if you would like to relocate in the city permanently, you should acquire urban hukou. Failures in attempts at hukou conversion may result in strain, alienation or worse, self-estrangement. If you fail to be adapted to urban biology, you have to return to rural areas and become a return migrant.

The mechanism is driven by market dynamics produced in transition China. Since 1978, China has taken steps to move from non-viable central administrative command planning (socialism) toward a full market system (capitalism), while retaining the communist party's hold on political power and expanding quasi-private property rights without, however, fully privatising the large, capital-intensive, state-owned industrial sector. General features of migrants had been a major social focus in the last 30 years. Rural migrants are often economically or politically oppressed. Regardless of economic cost, it can be very difficult to move from the country to the big city. Some persons had a very hard time adjusting to rural life when you are used to rural settings.

Completing rural-urban migration and attempting to relocate in cities, rural persons in China do experience a long series of wanderings or adventures, especially when filled with notable experiences, hardships, etc. It is their Odyssey journey. The move odyssey start point may at the rural place, the final point may be cities or rural place. Therefore they would like to present their move odyssey by periods. Since long you have wondered; are you and how and where you spent your adulthood, how you became an urban citizen, which factors contributed to your success, how your social relations have evolved, etc... The present story of Chinese moves odyssey will help the readers to find answers to all these questions briefly. Although Chinese move Odyssey is a long journey, millions of migrants strive for it in each year. As you say, to start up is to finish the half. 


\section{Academic identification}

Just as an old saying in China, once a family moves, it will suffer poverty more than three years (ban jia san nian qiong). Residential mobility in China is really a big event for a household to get happiness on moving into a new building in China. The Chinese old saying in the process of rural-urban migration and subsequent relocation in cities can be identified in academic report.

Residential mobility can be conceptualised as an outcome of a choice process exercised under complex institutional and personal constraints. China's rather unique pattern of housing market segmentation under market transition impinges directly on residential location and relocation. Using a retrospective survey (1949-1994) in 20 Chinese cities, Huang and Deng (2006) found that while the overall mobility is low, it has fluctuated significantly over time with a recent rising trend, which corresponds to historical changes in housing policies. Drawing upon data from a sample survey, Li and Siu (2001) report most moves resulting from commodity housing construction are of short distance, although the general direction is towards the urban periphery in Guangzhou. Hukou registration retards their Residential mobility. Based on the reality of China, Liu (2011) shows labour trans-regional flow influence the regional economic growth. Based on a theoretical framework and empirical evidence from a survey, Zhu (2007) argues that the temporary nature of the floating population is a result of not only the hukou, but also the combined effects of the intrinsic demand of the industrial society for temporary migrants, the household strategy of migrants to diversify and maximise economic opportunities and spread economic risk, and certain conditions of the current stage of development. But, some factors barriers residential mobility in China.

$\mathrm{Li}$ and Gibson (2013) report over 100 million migrants without considering hukou conversion migrates into cities for most of the first three decades of the reform era. Labour flow is the prequisition for residential mobility in China. But, it is often retarded by institutional constraints. Since the late 1970s, China has made enormous efforts to liberalise its markets and integrate itself into the world economy. At this stage, Burgio (2007) argues dreams that the country's economic liberalisation will someday lead to democracy remain distant. Yes, we all agree with Burgio (2007). China's political elite has been more interested in defending the interests of this nascent capitalist class than that of the workers. Workers frequently complain of layoffs without pensions, abuse on the job, and work with no pay. Ge and Yang (2011) find that rural workers expanded off-farm work when mobility restrictions were lifted, interprovincial migration responded to expected earnings and local employment conditions, and returns to education converged gradually to the international standard.

Many researchers document the process of rural-urban migration in China. For example, using data from two national probability sample surveys in 1996 and 2008, Treiman (2012) describes inequality trends in various aspects of inequality for three groups aged 14: those with rural registration and rural residence; those with rural registration and urban residence; and those with urban registration. The specific outcomes considered are education, occupational position, earnings, family income, material well-being, and perceptions regarding whether life has improved. Liu (2005) reveals that the two major contributing factors to rural-urban inequality are low educational attainment among rural population and low rewards to education in rural employment. Using data from a recent Chinese household survey, Liu (2005) find that people who obtained urban hukou late in their lives fared significantly less well than other urban 
residents. They have fewer years of education, are less likely to hold state sector jobs and to have employer-provided healthcare benefits, and are more likely to be self-employed or unemployed. A rural-urban comparison that controls for factors commonly believed to affect migration decision reveals that the two major contributing factors to rural-urban inequality are low educational attainment among rural population and low rewards to education in rural employment. Since the hukou denies rural population the access to education and urban employment, Liu (2005) argue that the hukou is a major contributing factor to rural-urban inequality.

Recent research literature on migration in China has mainly focused on desire of settling down in urban areas. As more and more people participate in the migration process and as migrants expand the duration of their stays in cities. Using data from the 1995 China 1\% population sample survey, Liang and Chen (2007) shows temporary migrant children without local hukou are much less likely to be enrolled in school compared to local children. Temporary migrants with less than one year of residence in cities suffer the most. A household survey in Shanghai show that residential relocation is accompanied by the changes in housing tenure, housing conditions, and the improved built form of planned residential districts $(\mathrm{Wu}, 2004)$. A huge new floating population of rural-urban migrants originates from Chinese economy reforms. Seeborg et al. (2000) found that Chinese policy reforms in both rural and urban areas decreased the balkanisation of labour markets and opened up employment opportunities for many rural-urban migrants. Agricultural reforms produced a large surplus labour supply. Urban reforms beginning in the 1980s simultaneously created an effective demand for rural migrants.

Most studies on institutional discrimination against migrants in Chinese cities focus on wage differentials. Zhang (2010) shows institutional discrimination reduces the number of jobs available to the migrants, increases their job search costs and the cost of losing jobs, and constrains migrants in changing jobs. Zhang (2010) shows that temporary migrants have longer job durations and shorter unemployment durations than local people or permanent migrants. Moreover, migrants start to change jobs more often only after they have stayed in the city for some time and have accumulated enough assets to be able to survive when unemployed. Cheng et al. (2013) demonstrate the existence of the dual divides in the urban labour market in China, and show that, compared with urban locals, rural migrants suffer employment and wage discrimination, while urban migrants suffer only employment discrimination. Using data from the 2002 CHIP survey, Jiang et al. (2012) find that people feel unhappy with between-group inequality, as measured by the income gap between migrants without local urban hukou and urban residents, irrespective of whether they are urban residents with or without local hukou. However, when we control for identity-related inequality and other individual, household, and city-level characteristics, inequality positively correlates with happiness. Liu (2005) argues that the hukou is a major contributing factor to rural-urban inequality.

Empirically, Zhang (2010) finds institutional discrimination in China reduces the number of jobs available to the migrants, increases their job search costs and the cost of losing jobs. Even though migrants take jobs unacceptable to local residents, the effects of this institutional discrimination still constrain migrants in changing jobs. Temporary migrants have longer job durations and shorter unemployment durations than local people or permanent migrants. Moreover, migrants start to change jobs more often only after they have stayed in the city for some time and have accumulated enough assets to be able to survive when unemployed. 
Most of floating population take the temporary form of migration, and maintain their double (rural and urban) residential status. Zhu (2007) argues that the temporary nature of the floating population is a result of not only the hukou, but also the combined effects of the intrinsic demand of the industrial society for temporary migrants, the household strategy of migrants to diversify and maximise economic opportunities and spread economic risk, and certain conditions of the current stage of development. Using household data collected in 2000, Wang (2003) concluded that not all migrants in China are 'floating' or 'temporary' residents. Some of them had been in the city for many years. However, their living and working conditions remained very poor. Government policies were major barriers for the integration of migrants with local residents (Wang, 2003). For example, the formation of a transitory identity as a 'guest Beijinger' results from the conflict of 'hukou' restriction and place identity ( $\mathrm{Li}, 2013)$. Li (2013) shows floating migrant workers make effort to settle in the suburban area of Beijing and hukou affecting their identity formation as 'guest Beijingers'. Residential displacement is contentious issues.

With the China General Social Survey (CGSS) data, Hu et al. (2011) show that compared with their circular counterparts, permanent migrants tend to stay within the home provinces and are more likely to have stable jobs and earn high incomes and thus are more adapted to urban lives. Hu et al. (2011) also find that more educated and more experienced migrants tend to be permanent urban residents, while the relationship of age and the probability of permanent migration is inverse U-shaped. Due to the restrictions of the current hukou and the lack of rural land rental market, those people with more children and more land at home are more likely to migrate circularly rather than permanently.

\section{An empirical exploration}

In fact, it is difficult to find the appropriate data for the purpose of examining difficulties of residential mobility related to familial relationships, economic affordability, and hukou conversion.

\subsection{Data}

To my knowledge, the most appropriate dataset surveying China providing direct residential mobility and hukou conversion variables is CHARLS Pilot data in China released by Zhao Yaohui's team. CHARLS Pilot data have indirect variables to represent for hukou conversion, marriage change, and move variable. Respondents in CHARLS are over 45 years old. Here, relevant variables are constructed from Zhao's questionnaire. See Table 1.

The present study aims at examining the impact of socioeconomic context on residential mobility from rural place to urban place in Chinese context. Thus, the following hypotheses are addressed

1 outmigration years is expected to have a negative influence on years prepared for moving within the county/city

2 years with the agricultural hukou is expected to have a negative influence on the move Odyssey. 
Table 1 Main variable description

\begin{tabular}{|c|c|}
\hline Variables & Descriptions \\
\hline \multicolumn{2}{|l|}{ Dependent variables } \\
\hline $\begin{array}{l}\text { Years prepared for moving } \\
\text { within the county/city }\end{array}$ & $\begin{array}{l}\text { Year first live in this village/neighbourhood minus year first } \\
\text { live in this county/city }\end{array}$ \\
\hline $\begin{array}{l}\text { Years prepared for moving } \\
\text { into the county/city }\end{array}$ & $\begin{array}{l}\text { Year most recently live in this county/city minus year first } \\
\text { live in this county/city }\end{array}$ \\
\hline \multicolumn{2}{|l|}{ Independent variables } \\
\hline Gender & $1=$ male, $2=$ female \\
\hline Age & 2010-birth year \\
\hline Married times & How many times have you been married? \\
\hline Outmigration years & Years away from current hukou county/city \\
\hline $\begin{array}{l}\text { Years with the agricultural } \\
\text { hukou }\end{array}$ & $\begin{array}{l}\text { The ending year having the agricultural hukou minus the } \\
\text { beginning year having the agricultural hukou }\end{array}$ \\
\hline Local migration years & $\begin{array}{l}\text { Year first live in this village/neighbourhood minus year live } \\
\text { in this county/city }\end{array}$ \\
\hline Lifespan mobility & Year first live in this county/city minus birth year \\
\hline
\end{tabular}

\subsection{Results}

I conduct two sets of regressions to examine the above hypothesis in Tables 2 and 3 . The coefficients of years with the agricultural hukou are significantly negative, suggesting that Hypothesis 1 is rejected. The coefficients of outmigration years with positive sign in Table 2 and negative sign in Table 3 indicates it is more easy to collect social relationships in local place than in non-local place. Moreover, lifespan mobility in Table 3 has negative impact on years prepared for moving into the county/city. The coefficients of age in Tables 2 and 3 are positive. The coefficients of married times in Table 2 are positive. This indicates it is urban dream that damage and disintegrate many rural families.

Some results of this research support existing observations. Huang and Deng (2006) show that while some factors such as change of marital status and work units have consistent effects on mobility over time. Nielsen et al. (2011) confirm that hukou status does moderate the job satisfaction-subjective well-being relationship. Chinese farm families under the hukou have the land use-rights but not the rights of alienation. If permanently leaving agriculture, they have to return the land to local authorities and consequently give up a stream of future land earnings. The deterrent effect of this land arrangement on labour mobility by constructing a household model which considers both part-time farming and permanent migration decisions (Yang, 1997). The coefficients on lifespan mobility and years with the agricultural hukou are negative significantly. The findings are generally consistent with the previous studies that in order to create non-farm jobs, both town-village enterprise strategy and small-city strategy aim to deter rural population's entry into large cities (Chen and Gao, 2011). 
Table 2 Regression on years spent moving within the county/city

\begin{tabular}{lccc}
\hline & Model 1 & Model 2 & Model 3 \\
\hline Gender & $-3.495598^{* * *}$ & -2.921543 & $5.869219^{* *}$ \\
& $(1.274952)$ & $(2.086151)$ & $(2.840574)$ \\
Age & $.5935105^{* * *}$ & $.4119274 * * *$ & \\
& $(.0589341)$ & $(.0899749)$ & \\
Years with the agricultural hukou & & $-.2119814 * *$ & \\
Outmigration years & & $(.0829996)$ & \\
Married times & & & $.3259335^{* *}$ \\
& & & $(.1354527)$ \\
cons & & & $16.28408^{* * *}$ \\
& & & $(4.650412)$ \\
R-squared & $(4.291418)$ & $(6.673863)$ & $-19.72737 * * *$ \\
Adj. R-squared & 0.1488 & 0.1387 & 0.2213 \\
Number of obs. & 0.1462 & 0.1256 & 0.1884 \\
\hline Notes: & 651 & 200 & 75 \\
\hline
\end{tabular}

Notes: ${ }^{* * *} p<0.01 ; * * p<0.05 ;{ }^{*} p<0.1$.

Table 3 Regression on years prepared for moving into the county/city

\begin{tabular}{lccc}
\hline & Model 1 & Model 2 & Model 3 \\
\hline Local migration years & $\begin{array}{c}.3944659^{* * *} \\
(.0795872)\end{array}$ & & \\
Age & & $.6296351^{* * *}$ & \\
Lifespan mobility & & $(.1123211)$ & \\
& & $-.7276981^{* * *}$ & \\
Years with the agricultural hukou & & $(.0535631)$ & \\
& & & $-.2704363^{* *}$ \\
Outmigration years & & & $(.1343555)$ \\
& & $-.189195^{*}$ & \\
cons & & $(.1031708)$ & $12.23092^{* * *}$ \\
& & 6.101875 & $(3.155731)$ \\
R-squared & $(2.356516)$ & $(6.006532)$ & 0.0623 \\
Adj. R-squared & 0.1911 & 0.8332 & 0.0469 \\
Number of obs. & 0.1833 & 0.8197 & 63 \\
\hline
\end{tabular}

Notes: $* * * p<0.01 ; * * p<0.05 ; * p<0.1$.

\subsection{Analysis}

The above results can be explained and illustrated by the prior researches. Two representative surveys relating to 1995 and 1999 show labour market is still at a rudimentary stage and job mobility remains low (Knight and $\mathrm{Li}, 2005$ ). Based on the sample data of population censuses in 1990 and 2000, Wu (2010a) show that during the 
decade, children of rural-hukou became more disadvantaged compared to their urban counterparts, and the effect of their father's socioeconomic status on school enrolment was enhanced. Knight and Yueh (2004) shows a distinction is made between the institutionally favoured urban residents and the rural-urban migrants whose mobility rate of migrants greatly exceeds that of urban residents. Liu (2005) find that people who obtained urban hukou late in their lives fared significantly less well than other urban residents. They have fewer years of education, are less likely to hold state sector jobs and to have employer-provided healthcare benefits, and are more likely to be self-employed or unemployed. In fact, limited family educational background, poor quality of school education and unstable community environment were common experiences among the migrant youths. In addition, the hukou and other social policies that restricted education opportunities for these migrant youths contributed to the class reproduction process.

Zhang et al. (2008) shows that Chinese social status, hukou, plays an important role as a catalyst in the simultaneous processes of income distribution and tourist commercialisation. By analysing narratives from a survey of peasant households in Sichuan and Anhui, Fan (2004) emphasise the central role of state policies and institutions, especially the hukou, in channelling peasants to specific sectors and jobs and creating an exploitative migrant labour regime. The incorporation of maiden workers into migrant work and the relative absence of married women in the rural-urban migrant labour force, reflect interactions between institutional controls, gender ideology, and demands of the migrant labour regime. Lu (2008) find that China's social stratification is characterised by the simultaneous existence of differentiation between urban and rural hukou and hierarchy within urban hukou; furthermore, there is a positive correlation between one's opportunities for social mobility and the possibility of changing and transferring one's hukou. Despite the increasing social mobility ensuing from market-oriented transformation, the hukou hierarchy and its structural influence on mobility within the institutional framework persist. The strongly conglutinative nature of the hukou has given rise to social disparities.

Based on a large-scale household survey conducted in Nanjing in 2005, He et al. (2008) confirms the enduring and widening urban-rural division, and suggests that rural migrants remain outside the urban society in terms of both living conditions and social welfare provision. Based on a case study of Nanjing, Chen (2012) finds the hukou has strong differential effects on poor families' housing conditions. Lau and Chiu (2013) also suggest that migrant workers were ineligible to apply for public housing due to the hukou.

Hukou conversion is the consequences of rural to urban registration (hukou) mobility. In contrast to massive rural-urban migration, hukou conversion is difficult and rare in contemporary China, but childhood urban residence increases the likelihood of achieving an urban hukou. Zhang and Treiman (2013) show that the effect of hukou conversion varies across hukou converters from different social origins.

Migration experience may go with poor physical health and psychological distress. For instance, using Data came from a household survey conducted in Beijing between May and October in 2009, Chen (2011) draws particular attention to the diminishing physical health advantage and the initial high level of psychological distress among urban-to-urban migrants. Jeong (2011) provides deeper insight that high-end alliance between the Beijing Government and large-scale real estate developers forced villagers and migrants out from their original locations to more remote, impoverished areas. 
Rural residential land represents one of the most important land use types in China. Wang et al. (2012) find that rural residential properties are inefficiently utilised under the existing land use regulations, that those who are younger and who had previous migration experiences are more likely to support the free trading of rural residential properties while the village cadres are more likely to oppose it.

\section{Discussion}

This study is consistent with the researches outlined earlier in China that the numbers of migrant families who are experiencing some form of residential mobility within the one city. Taking Beijing as a case study, Zhao (2013) analyses new trends in peri-urbanisation and the city's planning responses after 2000 in China. Zhao (2013) show that the percentage of temporary migrant residents continues to grow in the peri-urban region and the social inequalities in relation to quality of life between local people and migrants have increased there. In particular, there is a concentration of thousands of young and well-educated migrants in the peri-urban region, resulting in a new kind of urban slum. Sprawling development still dominates Beijing's fringe. New planning policies related to an urban-rural integration strategy have played a positive role in improving living conditions in rural areas and reducing the social and economic gaps between urban and rural areas in the peri-urban region. Growing market forces, and social discrimination caused by the remnants of the hukou mechanism.

This study is consistent with the researches outlined earlier in China that the number of families who are experiencing some form of housing stress is increasing. Huang and Deng (2006) argue that residential mobility in transitional China is mainly triggered by changes in housing supply and housing qualification, both of which are determined by housing policies. Jiang (2006) reveal that migrants do not necessarily live in poorer housing conditions than non-migrants in urban areas; some housing facilities for the floating population, who moved without changes in hukou, are even better than those of local urban residents. Zhang (2009) argues that during the period of transition, China's social assistance programme was not only a corollary of dealing with the challenge of poverty, but also had a close relationship with politics. In inquiring into urban meaning in the name of life, $\mathrm{Li}$ (2010) offers an academic approach and hope for the future through a critique of 'devitalised' urban space and advocacy of a new form of urban civilisation that will regulate and guide transformation in urban space under the principle of 'the good life'.

This study provides insights into regional development planning. Coordinated development strategy practiced in current China aim to reach a balanced development between the urban and rural sectors by making not only large cities more welcoming to rural migrants but also the small cities, towns, and areas where rural population now reside harder to leave (Chen and Gao 2011). Vendryes (2011) shows that, in fairly general circumstances, hukou-related migration constraints can actually hasten development, understood as the transfer of the labour force to the modern sector, driven by capital accumulation. Chen and Groenewold (2010) find that a policy reducing internal migration costs is effective in reducing the per capita output gap but does so at a substantial cost to the coast. Policies which improve agricultural productivity in the interior region are most likely to both reduce the gap and make both regions better-off. Changes in government consumption expenditure, central government fiscal 
redistributions and tax cuts, on the other hand, are less effective and have their long-run effectiveness reduced by migration.

Nearly all the academic circles in China believe hukou of permanent registration in China has supported growing relative inequality over the last 50 years by restraining labour migration both between the countryside and urban areas and between regions and cities. Whalley and Zhang (2007) argue that hukou has supported growing relative inequality over the last 20 years by restraining labour migration both between the countryside and urban areas and between regions and cities. Schoolman and Ma (2012) argue that, due in part to hukou, urban workers in China with an official rural residence may be subject to disproportionate exposure to environmental pollution. Hukou is also the resource of educational inquity. Lau and Li (2011) suggested that hukou status had impacts on family and school social capital accrued among primary school children in Shenzhen. Li et al. (2013) attempts to identify neighbourhood peer effects created by hukou on children's dropout decision in rural China.

Rural-urban migration flows are a crucial corollary of economic development. Hukou acts as a strong constraint on individual migration. It shows that, in fairly general circumstances, hukou-related migration constraints can actually hasten development, understood as the transfer of the labour force to the modern sector, driven by capital accumulation. The hukou could thus be one of the causes of the extremely high Chinese saving rate and of the high pace of Chinese development (Vendryes, 2011). China's hukou poses severe restrictions on labour mobility. The empirical study of the local timing of the rural hukou reforms in China from 1979 through 1987 showed that increasing the mobility of the rural labour force and thereby discouraging and delaying childbearing among rural Chinese (Schultz and Zeng, 1999). Bosker et al. (2012) argue relaxing hukou restrictions will increase labour mobility and in turn leads to further strengthen dominant place of immigrating cities in China's urban hierarchy. Currently, rules governing human movements within social systems are found by Szell et al. (2012). They report the motion of individuals is not only constrained by physical distances, but also strongly shaped by the presence of socio-economic areas. Gilbert and Wahl (2003) suggest that distortions in China's labour market, including imperfect labour mobility, rural-urban migration, dual urban markets and surplus rural labour, have significant effects on trade liberalisation outcomes and in some cases produce unexpected second-best results.

Over the past decade, significant real estate price increase China's major cities have experienced has been considered as main barriers of rural-urban migration. Fleisher et al. (1997) also find indirect evidence that higher housing rents increase the quantity of available housing, thus facilitating interprovincial migration to favoured areas. Chen et al. (2011) finds that the abolition of the policy on the provision of welfare housing in 1998 is an important milestone in Chinese urban housing reform, which resulted in the market-oriented urban housing provision system. Theoretically, Whalley and Zhang (2007) find urban house price rises retard rural-urban migration. Wu (2006) finds migrants who rent public housing as their initial housing choice are much less likely to make moves subsequently and experience a lower average mobility rate. Longer-term migrants seem to gain some degree of residential stability, making duration of residence the single most influential factor for mobility rate. However, the high rate of mobility is not necessarily driven by the need for tenure or even amenity as few migrants make the transition from renters to owners after years of living in the cities ( $\mathrm{Wu}, 2006)$. 
Future should strengthen policy construction. Zhao and Lu (2010) suggest that the remaining the unfair treatment of residents according to their hukou status may influence the floating worker's ability to connect housing and workplace opportunities that could reduce commuting time. Chen (2011) underlines the necessity to make fundamental changes to the restrictive hukou and the unequal distribution of resources and opportunities in urban and rural areas. These changes will lessen the pressure on big cities and improve the living conditions and opportunities of residents in townships/small cities and the countryside. With a two-sector model, Wang and Kalirajan (2002) identifies that removing institutional restrictions on intersectoral labour mobility has been instrumental in accelerating economic growth at the overall rural economy level. Treiman (2012) shows that the size of the rural-urban gap has remained relatively constant over a 60-year period. Whalley and Zhang (2007) believe impacts of removing hukou restrictions on migration are smaller, but are still significant. Removal of migration barriers is again inequality improving but less so. Citizenship in the Chinese context is interlocked with hukou instituted more than 50 years ago. Li et al. (2010) find facing a flood of migration, local government has introduced a residence card system without challenging the existing hukou in order to trade the differential citizenship for talents, capital, and super-low-cost labour and to avoid the social obligations to the non-constituents. Liu and Xu (2007) argue peasant workers' citizenisation can improve skills of rural migrants and help adjust themselves to urban lives. Relaxing hukou restrictions may result in poor outcomes. Relaxing hukou restrictions, Bosker et al. (2012) find that increased labour mobility leads to more pronounced core-periphery outcomes. Wang (2002) argues that both the phenomenon of occupational segregation and migration settlement related to native place ties will become less relevant due to the small cities and towns hukou-free policy. From 1985 to 1995, migration restrictions decline over time, which is associated with a greater responsiveness of mobility decisions to economic factors, underlining the reinforcement of labour market efficiency (Poncet, 2006).

Some factors may retard migration in cities. Theoretically, Hertel and Zhai (2006) show that the reforms in rural land rental market and hukou, as well as increasing off-farm labour mobility, would reduce the urban-rural income ratio dramatically. Lu et al. (2008) demonstrate the relationship between corruption and privatisation in China. Corruption and inequality are what the country pays for their dream of public ownership in 1950s. Equality, efficiency and maintaining current social and political structure cannot be achieved simultaneously during enterprise restructuring. Huang et al. (2010) suggests taking a 'beyond hukou' perspective to re-examine the social exclusion of rural-urban migrants in urban China. Xu et al. (2012) imply when people are able to choose a city to live in, they will take particular characteristics of natural environment quality and rates of economic development into account in order to improve their lifestyles. In fact, current move wave result in bad effects, such as overcrowded cities and people leave behind in the rural areas. In an analysis of the locations and emissions of pollution-producing facilities in China's Jiangsu province, Schoolman and Ma (2012) find that townships with a higher percentage of rural migrants are more likely to be exposed to high levels of air and water pollution. Hu (2002) shows that the improving trade condition and the increasing rural-to-urban labour mobility in China may be the reasons for the enlarging income gap between the coastal area and the hinterland. $\mathrm{Wu}$ (2013) argued that decentralisation has played a negative role in integrating the large 
number of migrant workers into local cities and promoting equity within social welfare delivery at a national level in China.

From the angle of degree of development, market system in transitional China is different from those in western countries. In order to illustrate how the market transition has led to earnings inequality in former state socialist countries, $\mathrm{Wu}(2010 \mathrm{~b})$ examine selective mobility of workers from the state sector to the market sector and reveals that recent entrants into the market are driven by two different institutional processes - some are self-selected for higher economic returns (voluntary entrants) and some are pushed into the market through layoffs (involuntary entrants), resulting in a more heterogeneous body of workers in the market sector than before. Some other studies can be thought in the scenario of $\mathrm{Wu}(2010 \mathrm{~b})$ and provide indirect evidences of move Odyssey in China. For example, income disparity results in unequal housing (Ren, 2012; Coulson and Tang, 2013). Opposite of expectation of Lee (1993), reform of housing, healthcare and other social welfare services reduce the chance of relocation in cities to some degree. The related demonstrations can be found in results of Gregory and Meng (1995), Lu (2002), Li and Zhang (2010) and Ho (2011). Freeman (2010) finds that contrary to the Harris-Todaro two-sector model in which rural-urban migration adjusts to produce a positive relation between unemployment and wages across regions and sectors, wages and unemployment are inversely related by the 'wage curve' in China.

\section{Conclusions}

Residential mobility is determined as a result of self-selection mechanisms that are affected by benefit-motivated. This study the role of hukou conversion and life improvement residential mobility in China using a new sample of middle aged and older Chinese respondents. The most striking results are those using shows that implying that. Our work on residential mobility in CHARLS relied on two complimentary measures that proxy for different dimensions of health during the mobility years.

Once you have a better life dream, your move may start. Key point of it is to master law of move. Understanding of the basic laws governing human motion remains limited owing to the lack of tools to monitor the time-resolved location of individuals. González et al. (2008) find that, in contrast with the random trajectories, human trajectories show a high degree of temporal and spatial regularity, each individual being characterised by a time-independent characteristic travel distance and a significant probability to return to a few highly frequented locations. And despite the diversity of their travel history, humans follow simple reproducible patterns. De Montjoye et al. (2013) study 15 months of human mobility data for one and a half million individuals and find that find a formula for the uniqueness of human mobility traces given their resolution and the available outside information. These findings represent fundamental constraints to an individual's privacy and have important implications for the design of frameworks and institutions dedicated to protect the privacy of individuals. Theoretically, Whalley and Zhang (2007) resulted when we remove migration restrictions all wage and most income inequality disappears. Shen (2013) indicates that some areas would first become major destinations of migration, to be followed by other areas later.

Rural to urban migration has made an important contribution to the urban economic development in China over the last two decades. Cities propel, create and the mediate the dynamics of economy that are released by the mutual reinforcement of activities 
clustering together. When urban dwellers have outnumbered the rural ones, the law of urban dynamics that future of cities depends largely on their capacity to generate and distribute wealth and the quality of life they offer to citizens may terminate. To keep urban sustainability, macro policy should scientifically be designed.

\section{References}

Bosker, M., Brakman, S., Garretsen, H. and Schramm, M. (2012) 'Relaxing hukou: increased labor mobility and China's economic geography', Journal of Urban Economics, Vol. 72, Nos. 2-3, pp.252-266.

Burgio, C. (2007) 'Democracy in China: a distant dream', Asia Europe Journal, Vol. 5, No. 2, pp.181-186.

Chen, A. and Gao, J. (2011) 'Urbanization in China and the coordinated development model - the case of Chengdu', The Social Science Journal, Vol. 48, No. 3, pp.500-513.

Chen, A. and Groenewold, N. (2010) 'Reducing regional disparities in China: an evaluation of alternative policies', Journal of Comparative Economics, Vol. 38, No. 2, pp.189-198.

Chen, G. (2012) 'Housing the urban poor in post-reform China: some empirical evidence from the city of Nanjing', Cities, Vol. 29, No. 4, pp.252-263.

Chen, J. (2011) 'Internal migration and health: re-examining the healthy migrant phenomenon in China', Social Science \& Medicine, Vol. 72, No. 8, pp.1294-1301.

Chen, J., Guo, F. and Wu, Y. (2011) 'One decade of urban housing reform in China: urban housing price dynamics and the role of migration and urbanization, 1995-2005', Habitat International, Vol. 35, No. 1, pp.1-8.

Cheng, Z., Guo, F., Hugo, G. and Yuan, X. (2013) 'Employment and wage discrimination in the Chinese cities: a comparative study of migrants and locals', Habitat International, Vol. 39, pp.246-255.

Coulson, N.E. and Tang, M. (2013) 'Institutional and demographic influences on the presence, scale and geographic scope of individual Chinese real estate investment', Regional Science and Urban Economics, Vol. 43, No. 2, pp.187-196.

Fan, C.C. (2004) 'The state, the migrant labor regime, and maiden workers in China', Political Geography, Vol. 23, No. 3, pp.283-305.

Fleisher, B.M., Yin, Y. and Hills, S.M. (1997) 'The role of housing privatization and labor-market reform in China's dual economy', China Economic Review, Vol. 8, No. 1, pp.1-17.

Freeman, R.B. (2010) 'Chapter 70 - labor regulations, unions, and social protection in developing countries: market distortions or efficient institutions?', Handbook of Development Economics, Vol. 5, pp.4657-4702.

Ge, S. and Yang, D.T. (2011) 'Labor market developments in China: a neoclassical view', China Economic Review, Vol. 22, No. 4, pp.611-625.

Gilbert, J. and Wahl, T. (2003) 'Labor market distortions and China's WTO accession package: an applied general equilibrium assessment', Journal of Comparative Economics, Vol. 31, No. 4, pp.774-794.

González, M.C., Hidalgo, C.A. and Barabási, A.L. (2008) 'Understanding individual human mobility patterns', Nature, Vol. 453, pp.479-482, doi:10.1038/06958.

Gregory, R.G. and Meng, X. (1995) 'Wage determination and occupational attainment in the rural industrial sector of China', Journal of Comparative Economics, Vol. 21, No. 3, pp.353-374.

He, S., Liu, Y., Wu, F. and Webster, C. (2008) 'Poverty incidence and concentration in different social groups in urban China, a case study of Nanjing', Cities, Vol. 25, No. 3, pp.121-132.

Hertel, T. and Zhai, F. (2006) 'Labor market distortions, rural-urban inequality and the opening of China's economy', Economic Modelling, Vol. 23, No. 1, pp.76-109. 
Ho, E.L.E. (2011) 'Caught between two worlds: mainland Chinese return migration, hukou considerations and the citizenship dilemma', Citizenship Studies, Vol. 15, Nos. 6-7, pp.643-658.

Hu, D. (2002) 'Trade, rural-urban migration, and regional income disparity in developing countries: a spatial general equilibrium model inspired by the case of China', Regional Science and Urban Economics, Vol. 32, No. 3, pp.311-338.

Hu, F., Xu, Z. and Chen, Y. (2011) 'Circular migration, or permanent stay? Evidence from China's rural-urban migration', China Economic Review, Vol. 22, No. 1, pp.64-74.

Huang, Y. and Deng, F.F. (2006) 'Residential mobility in Chinese cities: a longitudinal analysis', Housing Studies, Vol. 21, No. 5, pp.625-652.

Huang, Y., Guo, F. and Tang, Y. (2010) 'Hukou status and social exclusion of rural-urban migrants in transitional China', Journal of Asian Public Policy, Vol. 3, No. 2, pp.172-185.

Jeong, J.H. (2011) 'From illegal migrant settlements to central business and residential districts: restructuring of urban space in Beijing's migrant enclaves', Habitat International, Vol. 35, No. 3, pp.508-513.

Jiang, L. (2006) 'Living conditions of the floating population in urban China', Housing Studies, Vol. 21, No. 5, pp.719-744.

Jiang, S., Lu, M. and Sato, H. (2012) 'Identity, inequality, and happiness: evidence from urban China', World Development, Vol. 40, No. 6, pp.1190-1200.

Knight, J. and Li, S. (2005) 'Wages, firm profitability and labor market segmentation in urban China', China Economic Review, Vol. 16, No. 3, pp.205-228.

Knight, J. and Yueh, L. (2004) 'Job mobility of residents and migrants in urban China', Journal of Comparative Economics, Vol. 32, No. 4, pp.637-660.

Lau, J.C.Y. and Chiu, C.C.H. (2013) 'Dual-track urbanization and co-location travel behavior of migrant workers in new towns in Guangzhou, China', Cities, Vol. 30, pp.89-97.

Lau, M. and Li, W. (2011) 'The extent of family and school social capital promoting positive subjective well-being among primary school children in Shenzhen, China', Children and Youth Services Review, Vol. 33, No. 9, pp.1573-1582.

Lee, C. (1993) 'China's transition towards the market: 'socialization' of the safety net', China Economic Review, Vol. 4, No. 2, pp.169-180.

Li, L. (2010) 'The good life: criticism and construction of urban meaning', Social Sciences in China, Vol. 31, No. 4, pp.133-146.

Li, C. and Gibson, J. (2013) 'Rising regional inequality in China: fact or artifact?', World Development, in press, corrected proof, available online 6 April 2013.

Li, L., Li, S. and Chen, Y. (2010) 'Better city, better life, but for whom?: The hukou and resident card system and the consequential citizenship stratification in Shanghai', City, Culture and Society, Vol. 1, No. 3, pp.145-154.

Li, Q., Zang, W. and An, L. (2013) 'Peer effects and school dropout in rural China', China Economic Review, in press, accepted manuscript, available online 19 April 2013.

Li, S.M. and Siu, Y.M. (2001) 'Residential mobility and urban restructuring under market transition: a study of Guangzhou, China', The Professional Geographer, Vol. 53, No. 2, pp.219-229.

Li, T. and Zhang, J. (2010) 'What determines employment opportunity for college graduates in China after higher education reform?', China Economic Review, Vol. 21, No. 1, pp.38-50.

Li, W. (2013) 'Hukou' status, place affiliation and identity formation: the case of migrant workers in metropolitan Beijing', Procedia Environmental Sciences, Vol. 17, pp.842-851.

Liang, Z. and Chen, Y.P. (2007) 'The educational consequences of migration for children in China', Social Science Research, Vol. 36, No. 1, pp.28-47.

Liu, B. (2011) 'The study of labor mobility and its impact on regional economic growth', Procedia Environmental Sciences, Vol. 10, pp.922-928. 
Liu, C. and Xu, J. (2007) 'Second generation peasant workers and their citizenization', China Population, Resources and Environment, Vol. 17, No. 1, pp.6-12.

Liu, Z. (2005) 'Institution and inequality: the hukou system in China', Journal of Comparative Economics, Vol. 33, No. 1, pp.133-157.

Lu, D. (2002) 'Rural-urban income disparity: impact of growth, allocative efficiency, and local growth welfare', China Economic Review, Vol. 13, No. 4, pp.419-429.

Lu, M., Chen, Z. and Zhang, S. (2008) 'Paying for the dream of public ownership: case studies on corruption and privatization in China', Transition Studies Review, Vol. 15, No. 2, pp.355-373.

Lu, Y. (2008) 'Does hukou still matter? The household registration system and its impact on social stratification and mobility in China', Social Sciences in China, Vol. 29, No. 2, pp.56-75.

de Montjoye, Y.A., Hidalgo, C.A., Verleysen, M. and Blondel, V.D. (2013) 'Unique in the crowd: the privacy bounds of human mobility', Scientific Reports, Vol. 3, Article No. 1376, pp.1-5, doi:10.1038/srep01376.

Nielsen, I., Smyth, R. and Liu, Y. (2011) 'The moderating effects of demographic factors and hukou status on the job satisfaction-subjective well-being relationship in urban China', The International Journal of Human Resource Management, Vol. 22, No. 6, pp.1333-1350.

Poncet, S. (2006) 'Provincial migration dynamics in China: borders, costs and economic motivations', Regional Science and Urban Economics, Vol. 36, No. 3, pp.385-398.

Ren, X. (2012) 'Rights to housing: developing societies', International Encyclopedia of Housing and Home, pp.158-163.

Schoolman, E.D. and Ma, C. (2012) 'Migration, class and environmental inequality: exposure to pollution in China's Jiangsu Province', Ecological Economics, Vol. 75, pp.140-151.

Schultz, T.P. and Zeng, Y. (1999) 'The impact of institutional reform from 1979 through 1987 on fertility in rural China', China Economic Review, Vol. 10, No. 2, pp.141-160.

Seeborg, M.C., Jin, Z. and Zhu, Y. (2000) 'The new rural-urban labor mobility in China: causes and implications', The Journal of Socio-Economics, Vol. 29, No.1, pp. 9-56.

Shen, J. (2013) 'Increasing internal migration in China from 1985 to 2005: institutional versus economic drivers', Habitat International, Vol. 39, pp.1-7.

Szell, M., Sinatra, R., Petri, G., Thurner, S. and Latora, V. (2012) 'Understanding mobility in a social petri dish', Scientific Reports, 2, Article No. 457, doi:10.1038/srep00457.

Treiman, D.J. (2012) “The difference between heaven and earth': urban-rural disparities in well-being in China', Research in Social Stratification and Mobility, Vol. 30, No. 1, pp.33-47.

Vendryes, T. (2011) 'Migration constraints and development: hukou and capital accumulation in China', China Economic Review, Vol. 22, No. 4, pp.669-692.

Wang, H., Wang, L., Su, F. and Tao, R. (2012) 'Rural residential properties in China: land use patterns, efficiency and prospects for reform', Habitat International, Vol. 36, No. 2, pp.201-209.

Wang, M.Y. (2002) 'Small city, big solution? China's hukou system reform and its potential impacts', disP - The Planning Review, Vol. 38, No. 151, pp.23-29.

Wang, X. and Kalirajan, K.P. (2002) 'On explaining China's rural sectors' productivity growth', Economic Modelling, Vol. 19, No. 2, pp.261-275.

Wang, Y.P. (2003) 'Living conditions of migrants in inland Chinese cities', The Journal of Comparative Asian Development, Vol. 2, No. 1, pp.47-69.

Whalley, J. and Zhang, S. (2007) 'A numerical simulation analysis of (hukou) labour mobility restrictions in China', Journal of Development Economics, Vol. 83, No. 2, pp.392-410.

$\mathrm{Wu}$, F. (2004) 'Residential relocation under market-oriented redevelopment: the process and outcomes in urban China', Geoforum, Vol. 35, No. 4, pp.453-470.

Wu, L. (2013) 'Decentralization and hukou reforms in China', Policy and Society, Vol. 32, No. 1, pp.33-42. 
Wu, W. (2006) 'Migrant intra-urban residential mobility in urban China', Housing Studies, Vol. 21, No. 5, pp.745-765.

$\mathrm{Wu}, \mathrm{X}$. (2010a) 'Economic transition, school expansion and educational inequality in China, 1990-2000', Research in Social Stratification and Mobility, Vol. 28, No. 1, pp.91-108.

Wu, X. (2010b) 'Voluntary and involuntary job mobility and earnings inequality in urban China, 1993-2000', Social Science Research, Vol. 39, Nos. 3, pp.382-395.

Xu, Y., Sun, J., Zhang, J., Xu, Y., Zhang, M. and Liao, X. (2012) 'Combining AHP with GIS in synthetic evaluation of environmental suitability for living in China's 35 major cities', International Journal of Geographical Information Science, Vol. 26, No. 9, pp.1603-1623.

Yang, D.T. (1997) 'China's land arrangements and rural labor mobility', China Economic Review, Vol. 8, No. 2, pp.101-115.

Zhang, H. (2009) 'Poverty and politics the evolution of minimum living standard guarantee system in china in the period of transition', Asia Pacific Journal of Social Work and Development, Vol. 19, No. 2, pp.5-20.

Zhang, H. (2010) 'The hukou system's constraints on migrant workers' job mobility in Chinese cities', China Economic Review, Vol. 21, No. 1, pp.51-64.

Zhang, X., Ding, P. and Bao, J. (2008) 'Income distribution, tourist commercialisation, and hukou status: a socioeconomic analysis of tourism in Xidi, China', Current Issues in Tourism, Vol. 11, No. 6, pp.549-566.

Zhang, Z. and Treiman, D.J. (2013) 'Social origins, hukou conversion, and the wellbeing of urban residents in contemporary China', Social Science Research, Vol. 42, No. 1, pp.71-89.

Zhao, P. (2013) 'Too complex to be managed? New trends in peri-urbanisation and its planning in Beijing', Cities, Vol. 30, pp.68-76.

Zhao, P. and Lu, B. (2010) 'Exploring job accessibility in the transformation context: an institutionalist approach and its application in Beijing', Journal of Transport Geography, Vol. 18, No. 3, pp.393-401.

Zhu, Y. (2007) 'China's floating population and their settlement intention in the cities: beyond the Hukou reform', Habitat International, Vol. 31, No. 1, pp.65-76.

\section{Notes}

1 Hukou created in 1950s and plays an important role in resource allocation and interest distribution in rural-urban society in China. The relaxation and reform in the hukou system, was influential in the initial increase of migration in the 1980s. Subsequent increase in the migration scale from 1990 to 2000 was driven largely by rapid and unbalanced economic development in China. In late 2001, the Chinese Government allowed its peasants to become legal urban residents in all small cities and towns. On the other hand, the registration of temporary population was introduced in the whole country at almost the same time in 1985. It has one-off impact on migration. 